December 2017

\title{
JMASM 46: Algorithm for Comparison of Robust Regression Methods In Multiple Linear Regression By Weighting Least Square Regression (SAS)
}

Mohamad Shafiq

Universiti Sains Malaysia, Kelantan, Malaysia, shafiqmat786@gmail.com

Wan Muhamad Amir

Universiti Sains Malaysia, Kelantan, Malaysia, wmamir@usm.my

Nur Syabiha Zafakali

Universiti Sains Malaysia, Kelantan, Malaysia, syabiha_89@yahoo.com

Follow this and additional works at: http://digitalcommons.wayne.edu/jmasm

Part of the Applied Statistics Commons, Social and Behavioral Sciences Commons, and the Statistical Theory Commons

\section{Recommended Citation}

Shafiq, M., Amir, W. M., \& Zafakali, N. S. (2017). JMASM 46: Algorithm for Comparison of Robust Regression Methods In Multiple Linear Regression By Weighting Least Square Regression (SAS). Journal of Modern Applied Statistical Methods, 16(2), 490-505. doi: $10.22237 / \mathrm{jmasm} / 1509496020$ 


\section{JMASM 46: Algorithm for Comparison of Robust Regression Methods In Multiple Linear Regression By Weighting Least Square Regression (SAS)}

\author{
Mohamad Shafiq \\ Universiti Sains Malaysia \\ Kelantan, Malaysia
}

\author{
Wan Muhamad Amir \\ Universiti Sains Malaysia \\ Kelantan, Malaysia
}

\author{
Nur Syabiha Zafakali \\ Universiti Sains Malaysia \\ Kelantan, Malaysia
}

The aim of this study is to compare different robust regression methods in three main models of multiple linear regression and weighting multiple linear regression. An algorithm for weighting multiple linear regression by standard deviation and variance for combining different robust method is given in SAS along with an application.

Keywords: $\quad$ Multiple linear regression, robust regression, M, LTS, S, MM estimation

\section{Introduction}

Multiple linear regression (MLR) is a statistical technique for modeling the relationship between one continuous dependent variable from two or more independent variables. A typical data template is compiled in Table 1.

Table 1. Data template for multiple linear regression

\begin{tabular}{|c|c|c|c|c|c|c|}
\hline$i$ & $y_{i}$ & $x_{i 0}$ & $X_{i}$ & $X_{12}$ & .. & $X_{i p}$ \\
\hline 1 & $y_{1}$ & 1 & $X 11$ & $x_{12}$ & $\ldots$ & $x \neq p$ \\
\hline 2 & $y_{2}$ & 1 & $x_{21}$ & $X 22$ & $\ldots$ & $x_{2 p}$ \\
\hline . & . & . & . & . & & . \\
\hline . & . & . & . & . & & . \\
\hline$n$ & $y_{n}$ & 1 & $x_{n 1}$ & $x_{n 2}$ & $\ldots$ & $X_{n p}$ \\
\hline
\end{tabular}

Sources: Ahmad et al., 2016a; 2016b

Mohamad Shafiq is a postgraduate student in the School of Dental Sciences. Email him at shafiqmat786@gmail.com.Dr. Amir is an Associate Professor of Biostatistics. Email himatwmamir@usm.my. 


\section{SHAFIQ ET AL.}

It is used when there are two or more independent variables and a single dependent variable where the equation below shows the model population information:

$$
y_{i}=\beta_{0}+\beta_{1} x_{1 i}+\beta_{2} x_{2 i}+\beta_{3} x_{3 i}+L+\beta_{k} x_{k i}+\varepsilon_{i}
$$

where

$\beta_{0}$ is the intercept parameter, and

$\beta_{0}, \beta_{1}, \beta_{2}, \ldots, \beta_{k-1}$ are the parameters associated with $k-1$ predictor variables.

The dependent variable $Y$ is written as a function of $k$ independent variables, $x_{1}, x_{2}, \ldots, x_{k}$. A random error term is added to equation as to make the model more probabilistic rather than deterministic. The value of the coefficient $\beta_{i}$ determines the contribution of the independent variables $x_{i}$, and $\beta_{0}$ is the $y$-intercept (Ahmad et al., 2016a; 2016b). The coefficients $\beta_{0}, \beta_{1}, \ldots, \beta_{k}$ are usually unknown because they represent population parameters. Below is the data presentation for multiple linear regression. A general linear model in matrix form can be defined by the following vectors and matrices as:

$$
\mathbf{Y}=\left[\begin{array}{c}
Y_{1} \\
Y_{2} \\
\vdots \\
Y_{n}
\end{array}\right], \mathbf{X}=\left[\begin{array}{ccccc}
1 & X_{11} & X_{12} & \cdots & X_{1, p-1} \\
1 & X_{21} & X_{22} & \cdots & X_{2, p-1} \\
\vdots & \vdots & \vdots & & \vdots \\
1 & X_{n 1} & X_{n 2} & \cdots & X_{n, p-1}
\end{array}\right], \boldsymbol{\beta}=\left[\begin{array}{c}
\beta_{0} \\
\beta_{1} \\
\vdots \\
\beta_{p-1}
\end{array}\right] \text { and } \boldsymbol{\varepsilon}=\left[\begin{array}{c}
\varepsilon_{1} \\
\varepsilon_{2} \\
\vdots \\
\varepsilon_{n}
\end{array}\right]
$$

\section{Robust Regression}

Robust regression is a method used when the distribution of the residual is not normally distributed and there are some outliers which affect the model (Susanti et al., 2014). It detects the outliers and provides better results (Chen, 2002). A common method of robust regression is the $\mathrm{M}$ estimate, introduced by Huber (1973), which is as efficient as Ordinary Least Square (OLS), and is considered the simplest approach. The Least Trimmed Squares (LTS) estimation was introduced by Rousseeuw (1984), and is a high breakdown value method. So, too, is the $\mathrm{S}$ estimation, another high breakdown value method with a higher statistical 


\section{ALGORITHM FOR COMPARISON OF ROBUST REGRESSION METHODS}

efficiency than LTS estimation (Rousseeuw \& Yohai, 1984). The S estimation is used to minimize the dispersion of residuals. The MM estimation, a special type of $\mathrm{M}$ estimation introduced by Yohai (1987), combines high breakdown value estimation and efficient estimation. The $\mathrm{M}$ estimation has a higher breakdown value and greater statistical efficiency than the $\mathrm{S}$ estimation.

\section{Calculation for linear Regression using SAS}

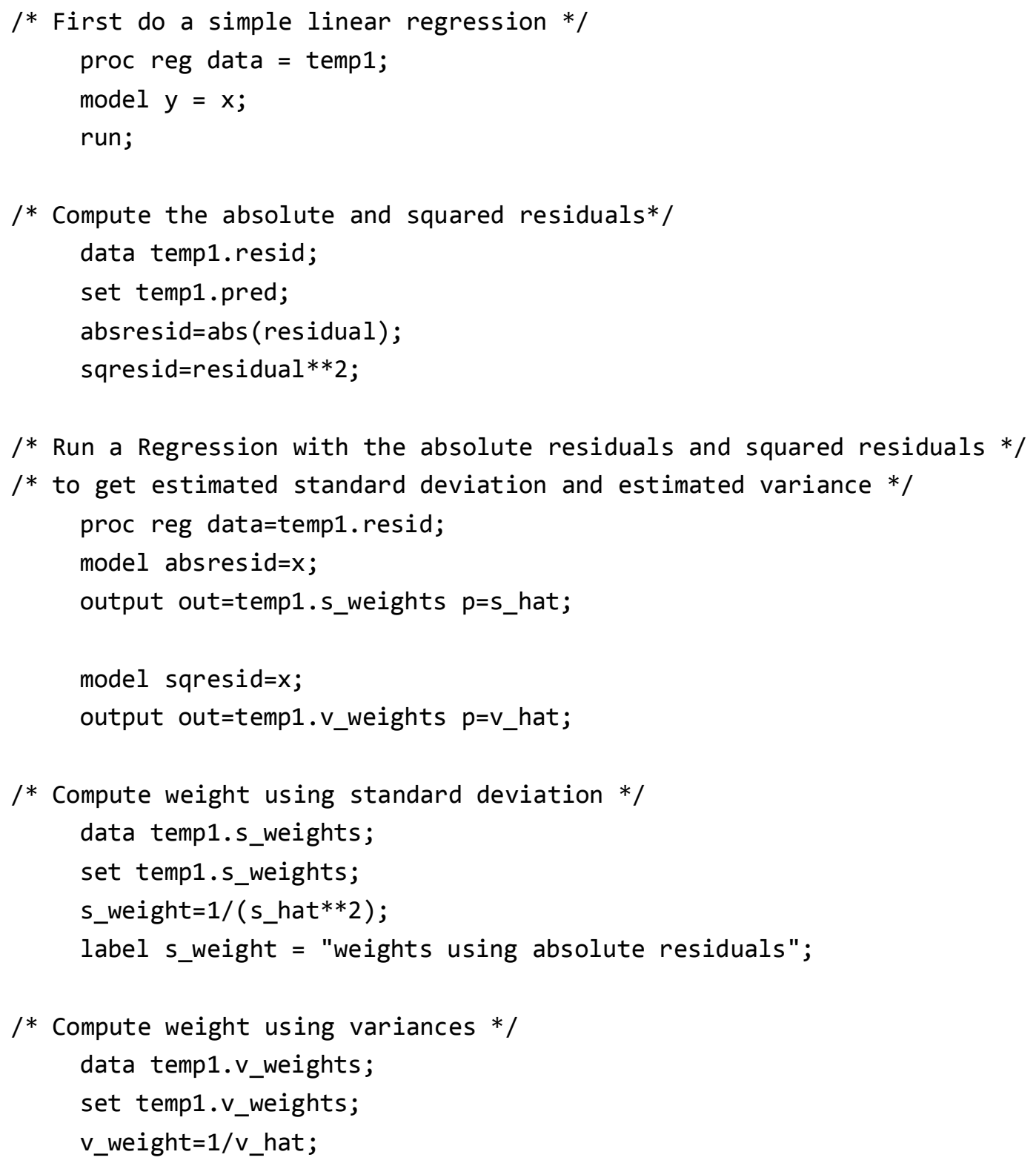




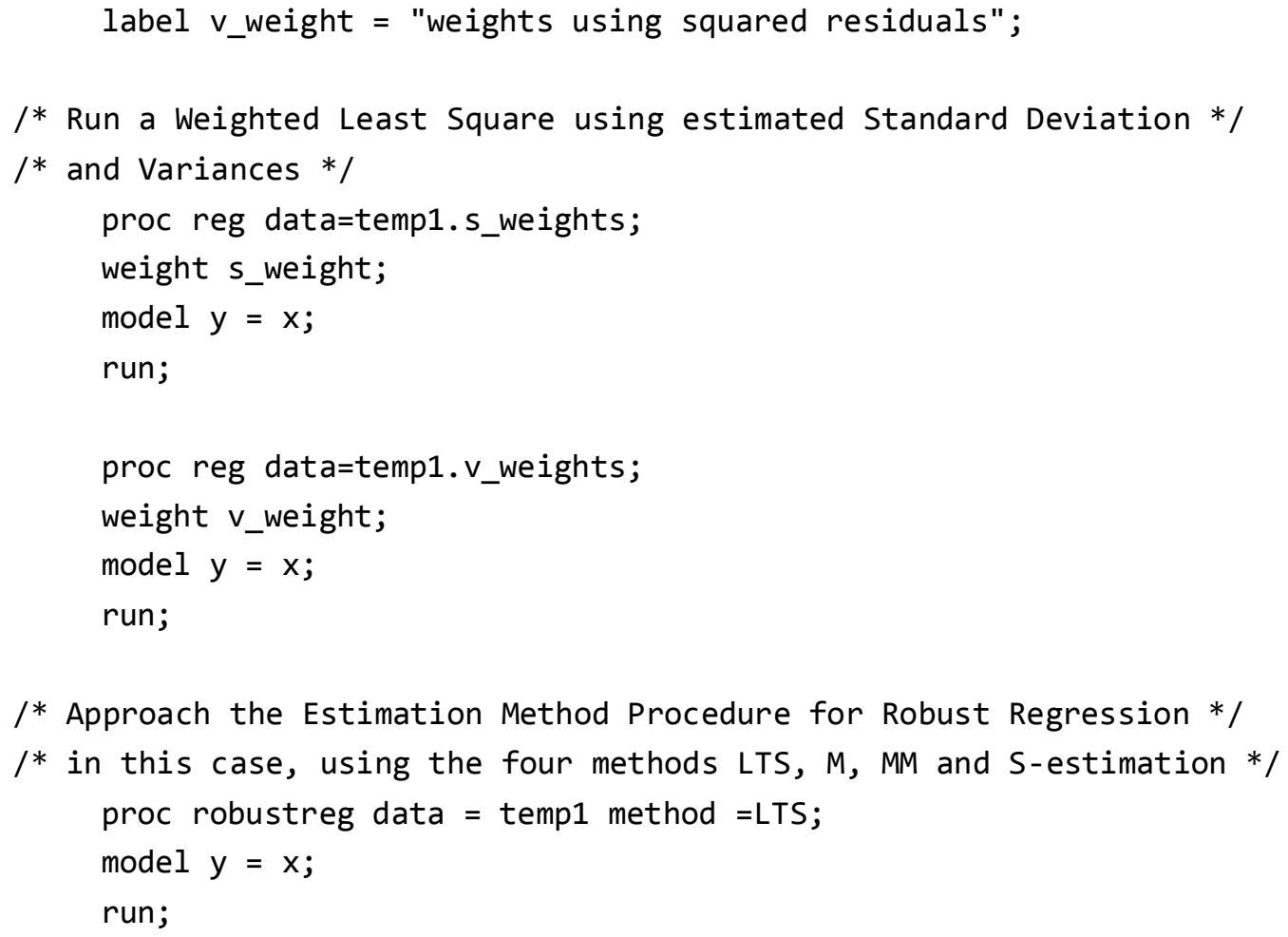

\section{An Illustration of a Medical Case}

A case study of triglycerides will illustrate the different methods for robust regression.

Table 1. Description of the variables

\begin{tabular}{lcl} 
Variables & Code & Description \\
\hline Triglycerides & Y & Triglycerides level of patients $(\mathrm{mg} / \mathrm{dl})$ \\
Weight & X1 & Weight $(\mathrm{kg})$ \\
Total Cholesterol & X2 & Total cholesterol of patients $(\mathrm{mg} / \mathrm{dl})$ \\
Proconvertin & X3 & Proconvertin $(\%)$ \\
Glucose & X4 & Glucose level of patients $(\mathrm{mg} / \mathrm{dl})$ \\
HDL-Cholesterol & X5 & High density lipoprotein cholesterol $(\mathrm{mg} / \mathrm{dl})$ \\
Hip & X6 & Hip circumference $(\mathrm{cm})$ \\
Insulin & X7 & Insulin level of patients $(\mathrm{IU} / \mathrm{ml})$ \\
Lipid & X8 & Taking lipid lowering medication $(0=\mathrm{no}, 1=$ yes $)$ \\
\hline
\end{tabular}

Sources: Ahmad \& Shafiq, 2013; Ahmad et al., 2014 


\section{Algorithm for Weighting Multiple Linear Model Regression by different Robust Regression Methods}

Title 'Alternative Modeling on Weighting Multiple linear regression'; Data Medical;

$\begin{array}{llllllllll}\text { input } & Y & X 1 & X 2 & X 3 & \text { X4 } & \text { X5 } & \text { X6 } & \text { X7 } & \text { X8; }\end{array}$

Datalines;

$\begin{array}{lllllllll}168 & 85.77 & 209 & 110 & 114 & 37 & 130.0 & 17 & 0 \\ 304 & 58.98 & 228 & 111 & 153 & 33 & 105.5 & 28 & 1 \\ 72 & 33.56 & 196 & 79 & 101 & 69 & 88.5 & 6 & 0 \\ 119 & 49.00 & 281 & 117 & 95 & 38 & 104.2 & 10 & 1 \\ 116 & 38.55 & 197 & 99 & 110 & 37 & 92.0 & 12 & 0 \\ 87 & 44.91 & 184 & 131 & 100 & 45 & 100.5 & 18 & 0 \\ 136 & 48.09 & 170 & 96 & 108 & 37 & 96.0 & 13 & 1 \\ 78 & 69.43 & 163 & 89 & 111 & 39 & 103.0 & 8 & 0 \\ 223 & 47.63 & 195 & 177 & 112 & 39 & 95.0 & 15 & 0 \\ 200 & 55.35 & 218 & 108 & 131 & 31 & 104.0 & 33 & 1 \\ 159 & 59.66 & 234 & 112 & 174 & 55 & 114.0 & 14 & 0 \\ 181 & 68.97 & 262 & 152 & 108 & 44 & 114.5 & 20 & 1 \\ 134 & 51.49 & 178 & 127 & 105 & 51 & 100.0 & 21 & 0 \\ 162 & 39.69 & 248 & 135 & 92 & 63 & 93.0 & 9 & 1 \\ 96 & 56.58 & 210 & 122 & 105 & 56 & 103.4 & 6 & 0 \\ 117 & 63.48 & 252 & 125 & 99 & 70 & 104.2 & 10 & 0 \\ 106 & 66.70 & 191 & 103 & 101 & 32 & 103.3 & 16 & 0 \\ 120 & 74.19 & 238 & 135 & 142 & 50 & 113.5 & 14 & 1 \\ 119 & 60.12 & 169 & 98 & 103 & 33 & 114.0 & 13 & 0 \\ 116 & 36.60 & 221 & 113 & 88 & 60 & 94.3 & 11 & 1 \\ 109 & 56.40 & 216 & 128 & 90 & 49 & 107.1 & 13 & 0 \\ 105 & 35.15 & 157 & 114 & 88 & 35 & 95.0 & 12 & 0 \\ 88 & 50.13 & 192 & 120 & 100 & 54 & 100.0 & 11 & 0 \\ 241 & 56.49 & 206 & 137 & 148 & 79 & 113.0 & 14 & 1 \\ 175 & 57.39 & 164 & 108 & 104 & 42 & 103.0 & 15 & 0 \\ 146 & 43.00 & 209 & 116 & 93 & 64 & 97.0 & 13 & 0 \\ 199 & 48.04 & 219 & 104 & 158 & 44 & 97.0 & 11 & 0 \\ 85 & 41.28 & 171 & 92 & 86 & 64 & 95.4 & 5 & 0 \\ 90 & 65.79 & 156 & 80 & 98 & 54 & 98.5 & 11 & 1 \\ 87 & 56.90 & 247 & 128 & 95 & 57 & 106.3 & 9 & 0 \\ 103 & 35.15 & 257 & 121 & 111 & 69 & 89.5 & 13 & 0\end{array}$


SHAFIQ ET AL.

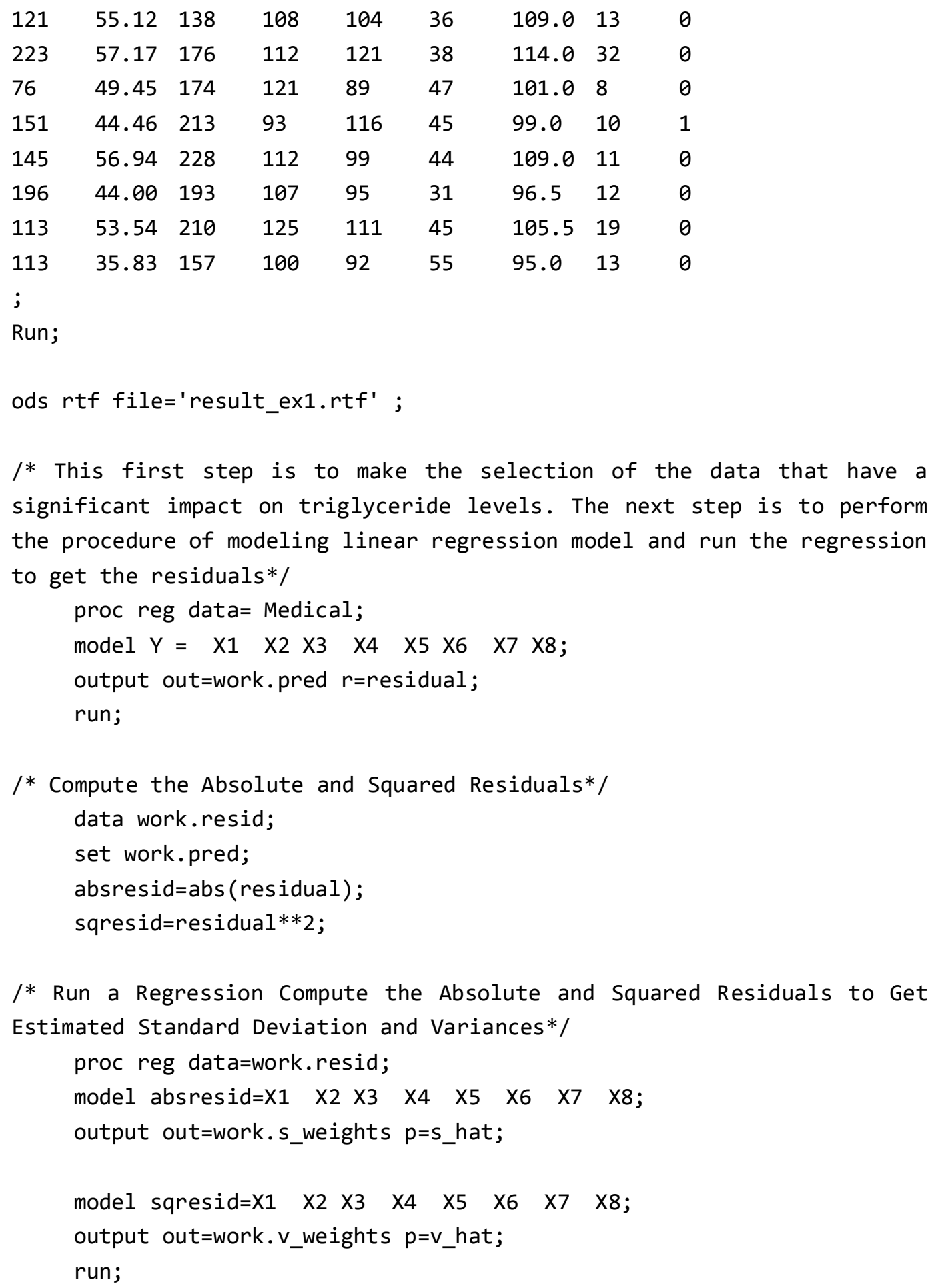




\section{ALGORITHM FOR COMPARISON OF ROBUST REGRESSION METHODS}

I* Compute the Weight Using Estimated Standard Deviation and Variances*/ data work.s_weights;

set work.s_weights;

s_weight=1/(s_hat**2);

label s_weight = "weights using absolute residuals";

data work.v_weights;

set work.v_weights;

v_weight=1/v_hat;

label v_weight = "weights using squared residuals";

/* Do a Weighted Least Squares Using the Weight from the Estimated Standard Deviation*/

proc reg data=work.s_weights;

weight s_weight;

model $\mathrm{Y}=\mathrm{X} 1 \quad \mathrm{X} 2 \quad \mathrm{X} 3 \quad \mathrm{X} 4 \quad \mathrm{X} 5 \quad \mathrm{X} 6 \quad \mathrm{X} 7 \quad \mathrm{X} 8$;

run;

/* Do a Weighted Least Squares Using the Weight from the Estimated Variances*/

proc reg data=work.v_weights;

weight v_weight;

model $\mathrm{Y}=\mathrm{X} 1 \quad \mathrm{X} 2 \quad \mathrm{X} 3 \quad \mathrm{X} 4 \quad \mathrm{X} 5 \quad \mathrm{X} 6 \quad \mathrm{X} 7 \quad \mathrm{X} 8$;

run;

/* Do Robust Regression, a Four Estimation Method to compare which are LTS, M, MM and S-Estimation For Weighted Least Square using estimated Standard Deviation*/

proc robustreg method=LTS data=work.s_weights;

weight s_weight;

model $\mathrm{Y}=\mathrm{X} 1 \quad \mathrm{X} 2 \quad \mathrm{X} 3 \quad \mathrm{X} 4 \quad \mathrm{X} 5 \quad \mathrm{X} 6 \quad \mathrm{X} 7 \quad \mathrm{X} 8$ / diagnostics leverage;

run;

/* Do a Robust Regression, a Four Estimation Method compare which are LTS, M, MM and S-Estimation For Weighted Least Square using estimated Variances*/

proc robustreg method=LTS data=work.v_weights;

weight v_weight; 
SHAFIQ ET AL.

model $\mathrm{Y}=\mathrm{X} 1 \quad \mathrm{X} 2 \quad \mathrm{X} 3 \quad \mathrm{X} 4 \quad \mathrm{X} 5 \quad \mathrm{X} 6 \quad \mathrm{X} 7 \quad \mathrm{X} 8$ / diagnostics leverage;

run;

\section{Results}

Compiled in Table 2 are the results from the multiple regression analysis using the original data. Compiled in Table 3 are the results for the weighted least square by standard deviation and weighted least square by variance. The residual plots do not indicate any problem with the model, as can be seen in Figures 1-3. A normal distribution appears to fit the sample data fairly well. The plotted points form a reasonably straight line. In our case, the residual plots bounce randomly around the 0 line (residual vs. predicted value). This supports the reasonable assumption that the relationship is linear.

Table 2. Parameter Estimates for Original Data

\begin{tabular}{crrr} 
Variables & Parameter Estimate & Standard Error & $\boldsymbol{P}$ value \\
\hline Intercept & -86.56544 & 102.93662 & 0.4070 \\
$x_{1}$ & -1.08598 & 0.95288 & 0.2634 \\
$X_{2}$ & -0.06448 & 0.21973 & 0.7712 \\
$x_{3}$ & 0.61857 & 0.36615 & 0.1015 \\
$\boldsymbol{X}_{4}$ & $\mathbf{1 . 1 0 8 8 2}$ & $\mathbf{0 . 3 3 9 8 9}$ & $\mathbf{0 . 0 0 2 8}$ \\
$x_{5}$ & -0.52289 & 0.57119 & 0.3673 \\
$X_{6}$ & 0.81327 & 1.38022 & 0.5601 \\
$\boldsymbol{X}_{7}$ & $\mathbf{2 . 7 7 3 3 9}$ & $\mathbf{1 . 2 5 0 2 6}$ & $\mathbf{0 . 0 3 4 3}$ \\
$x_{8}$ & 22.40585 & 14.51449 & 0.1331 \\
\hline
\end{tabular}

Table 3. Parameter Estimates for Weighted Multiple Linear Regression

\begin{tabular}{crrrrrr} 
& \multicolumn{2}{c}{ Weighted Least Square MLR (SD) } & \multicolumn{2}{c}{ Weighted Least Square MLR (V) } \\
\cline { 2 - 7 } Variables & $\begin{array}{r}\text { Parameter } \\
\text { Estimate }\end{array}$ & $\begin{array}{r}\text { Standard } \\
\text { Error }\end{array}$ & $\boldsymbol{P}$ value & $\begin{array}{r}\text { Parameter } \\
\text { Estimate }\end{array}$ & $\begin{array}{r}\text { Standard } \\
\text { Error }\end{array}$ & $\boldsymbol{P}$ value \\
\hline Intercept & -150.25787 & 90.05385 & 0.1056 & -139.33900 & 90.60374 & 0.1353 \\
$X_{1}$ & $\mathbf{- 1 . 3 0 6 9 4}$ & $\mathbf{0 . 5 9 4 2 3}$ & $\mathbf{0 . 0 3 5 7}$ & -1.19482 & 0.68833 & 0.0936 \\
$X_{2}$ & -0.01586 & 0.17670 & 0.9291 & 0.05784 & 0.19730 & 0.7716 \\
$X_{3}$ & 0.44460 & 0.35706 & 0.2227 & 0.36626 & 0.44451 & 0.4169 \\
$x_{4}$ & $\mathbf{0 . 8 9 1 0 6}$ & $\mathbf{0 . 3 8 2 4 0}$ & $\mathbf{0 . 0 2 6 7}$ & $\mathbf{1 . 0 1 3 5 9}$ & $\mathbf{0 . 3 7 2 5 3}$ & $\mathbf{0 . 0 1 1 1}$ \\
$X_{5}$ & -0.23352 & 0.44853 & 0.6064 & -0.24328 & 0.52342 & 0.6457 \\
$X_{6}$ & 1.74405 & 1.10677 & 0.1256 & 1.35688 & 1.20057 & 0.2680 \\
$X_{7}$ & $\mathbf{2 . 8 1 7 3 1}$ & $\mathbf{1 . 2 9 6 0 7}$ & $\mathbf{0 . 0 3 7 7}$ & $\mathbf{3 . 1 7 5 4 3}$ & $\mathbf{1 . 3 1 7 9 3}$ & $\mathbf{0 . 0 2 2 8}$ \\
$X_{8}$ & 16.87506 & 10.34963 & 0.1135 & 15.78743 & 12.16151 & 0.2048 \\
\hline
\end{tabular}




\section{ALGORITHM FOR COMPARISON OF ROBUST REGRESSION METHODS}

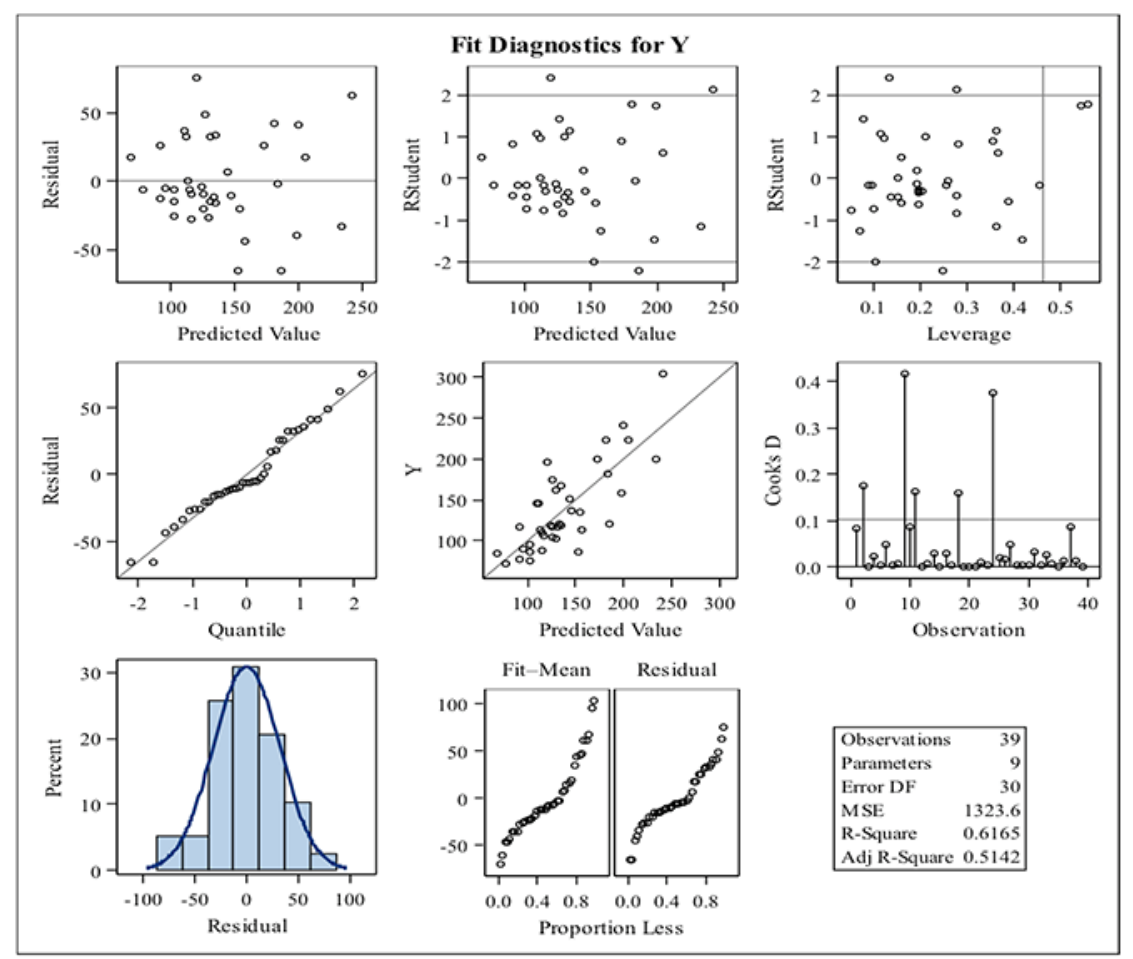

Figure 1. Fit Diagnostic for $y$ 
SHAFIQ ET AL.

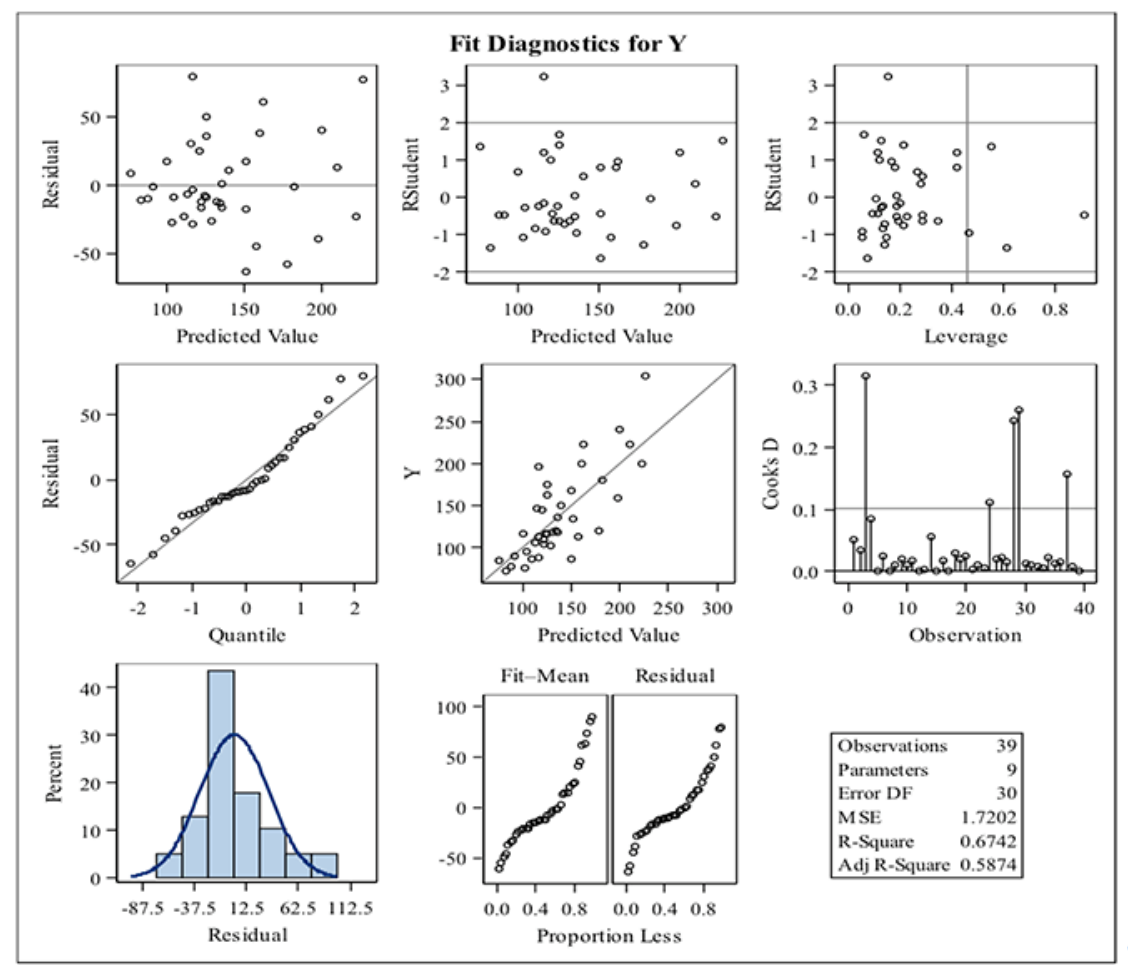

Figure 2. Fit Diagnostic for $y$-weighted least square using standard deviation 


\section{ALGORITHM FOR COMPARISON OF ROBUST REGRESSION METHODS}

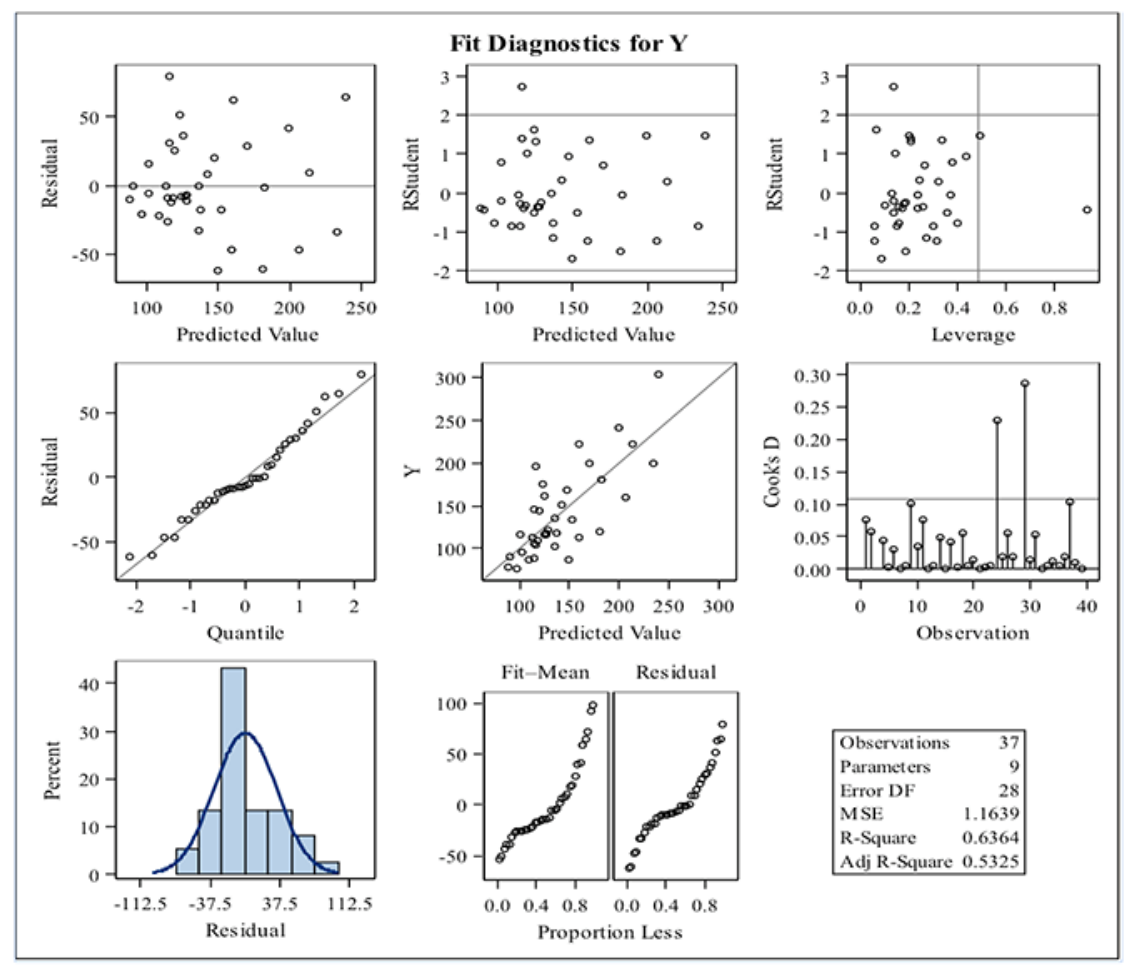

Figure 3. Fit Diagnostic for $y$-weighted least square using variances

Shown in Table 2 are the variables $x_{4}(p=0.0028)$ and $x_{7}(p=0.0343)$ were statistically significant for the multiple regression analysis. Shown in Table 3 are the variables $x_{1}(p=0.0357), x_{4}(p=0.0267)$ and $x_{7}(p=0.0377)$, which were statistically significant for weighted least square by standard deviation. The weighted least square by variance model shows the variable $x_{4}(p=0.0111)$ and $x_{7}$ ( $p=0.0028)$. RMSE is the square root of the variance of the residuals. It indicates the absolute fit of the model to the data, which are to observe how close the data points are to the model predicted values. Lower value of RMSE indicated a better fit. The RMSE for weighted least square by variance (1.08) shows a lower value compared to the weighted least square standard deviation (1.31) and multiple regression (36.4). A higher R-squared value indicated how well the data fit the model and also indicates a better model. The model multiple regression analysis has R-squared of 0.62 , weighted standard deviation multiple regression has Rsquared of 0.67 and weighted variance multiple regression has R-squared of 0.63. 


\section{SHAFIQ ET AL.}

Shown in Table 4 is a comparison of the models - multiple linear regression (model 1), weighted least square by standard deviation (model 2) and weighted least square by variance (model 3) - using the four different robust methods, which are $\mathrm{M}$ estimation, LTS estimation, $\mathrm{S}$ estimation and MM estimation. The LTS estimation has high R-squared in three of the models compared to other robust methods. The $\mathrm{S}$ estimation also has high $\mathrm{R}$-squared compared to $\mathrm{MM}$ and M estimation.

Table 4. Comparison of Model by using different Robust Method

\begin{tabular}{lccccccccc} 
& \multicolumn{3}{c}{ Model 1 } & \multicolumn{3}{c}{ Model 2 } & \multicolumn{3}{c}{ Model 3 } \\
\cline { 2 - 10 } Method & Outlier & Leverage & $R^{2}$ & Outlier & Leverage & $R^{2}$ & Outlier & Leverage & $R^{2}$ \\
\hline$M$ & 0.0000 & 0.2051 & 0.4662 & 0.0769 & 0.2051 & 0.5761 & 0.1622 & 0.1892 & 0.5090 \\
LTS & 0.1282 & 0.2051 & 0.7289 & 0.1282 & 0.2051 & 0.7289 & 0.1351 & 0.1892 & 0.7032 \\
$S$ & 0.0000 & 0.2051 & 0.5230 & 0.0000 & 0.2051 & 0.6079 & 0.0000 & 0.1892 & 0.5232 \\
MM & 0.0000 & 0.2051 & 0.4602 & 0.0000 & 0.2051 & 0.5843 & 0.0000 & 0.1892 & 0.5214 \\
\hline
\end{tabular}

From Figure 4-6 there is a detection of outlier in observations. They present a regression diagnostics plot (a plot of the standardized residuals of robust regression LTS versus the robust distance). As indicated in Figure 4 and 5, observation 37 is identified as outlier. The observations of 2, 9, 24, and 27 are identified as outlier and leverage. Observations 10,18 and 33 are identified as leverage point. In Figure 6, observation 35 is identified as outlier, observations 2, 8, 23, and 26 are identified as outlier and leverage, and observations 10, 17 and 27 are identified as leverage. The leverage plots available in SAS software are considered useful and effective in detecting multicollinearity, non-linearity, significance of the slope, and outliers (Lockwood \& Mackinnon, 1998). 


\section{ALGORITHM FOR COMPARISON OF ROBUST REGRESSION METHODS}
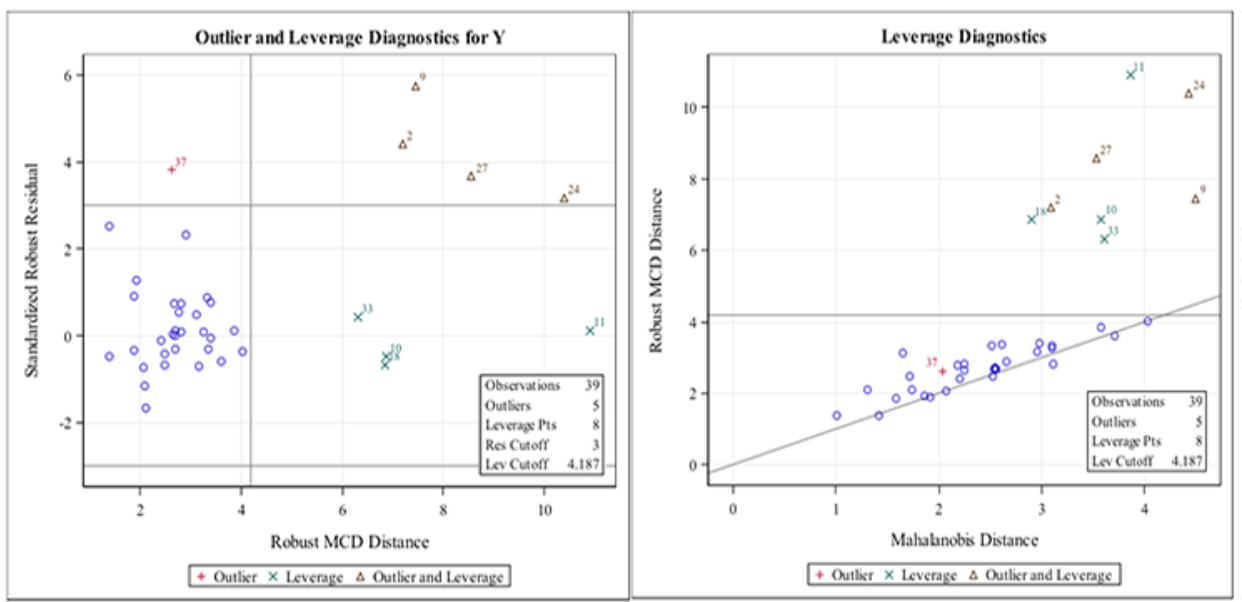

Figure 4. Outlier and Leverage Diagnostic for Y using LTS (Model 1)
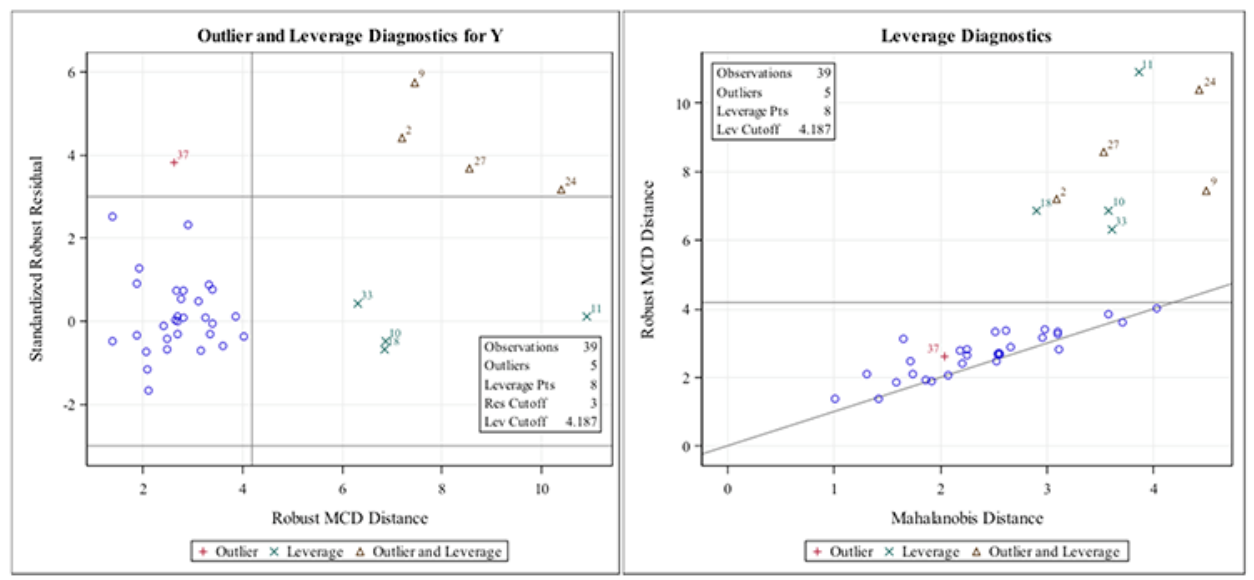

Figure 5. Outlier and Leverage Diagnostic for Y using LTS (Model 2) 


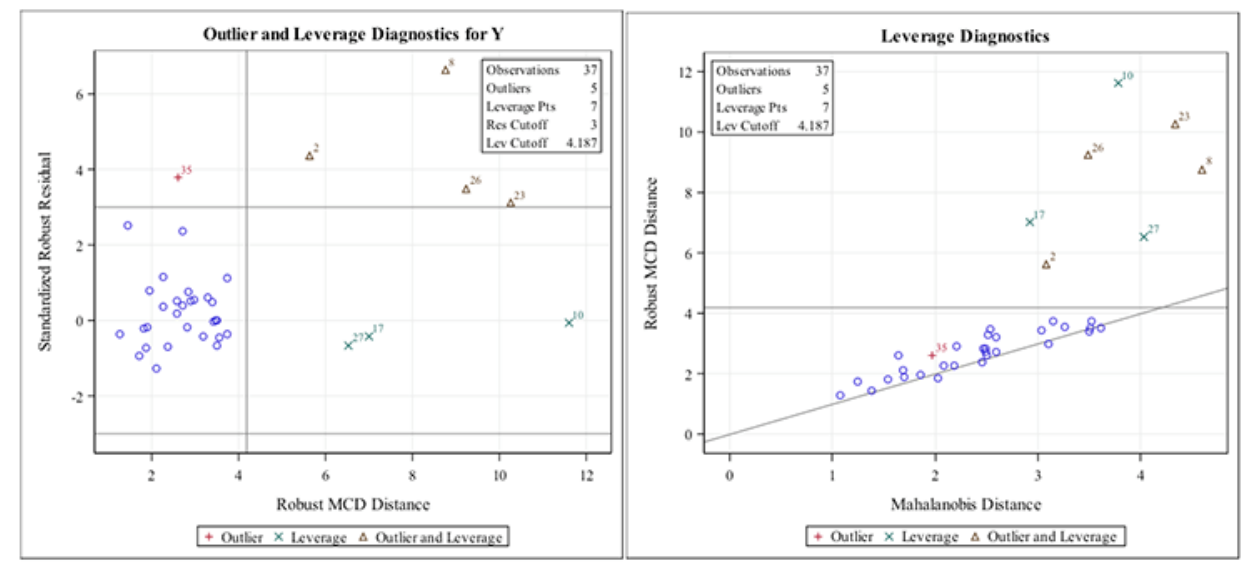

Figure 6. Outlier and Leverage Diagnostic for Y using LTS (Model 3)

\section{Conclusion}

SAS code for four different methods of robust regression was considered: $M$ estimation, LTS estimation, S estimation, and MM estimation. They provide a better understanding of the weighted multiple linear regression and different robust method underlying of relative contributions.

\section{Acknowledgements}

The authors would like to express their gratitude to Universiti Sains Malaysia for providing research funding (Grant 304/PPSG/61313187, School of Dental Sciences, Universiti Sains Malaysia).

\section{References}

Ahmad, W. M. A. W., \& Shafiq, M. (2013). High density lipoprotein cholesterol predicts triglycerides level in three distinct phases of blood pressure. International Journal of Sciences: Basic and Applied Research, 10(1), 38-46.

Retrieved from http://gssrr.org/index.php?journal=JournalOfBasicAndApplied\&page=article\&op $1=$ view \&path $\% 5 B \% 5 \mathrm{D}=1111 \&$ path $\% 5 \mathrm{~B} \% 5 \mathrm{D}=1098$. 


\section{ALGORITHM FOR COMPARISON OF ROBUST REGRESSION METHODS}

Ahmad, W. M. A. W., Shafiq, M., Nurfadhlina, H., \& Nor Azlida, A. (2014). A study of triglycerides level in three distinct phases of human blood pressure: A case study from previous projects. Applied Mathematical Sciences, 8(46), 22892305. doi: 10.12988/ams.2014.42145.

Ahmad, W. M. A. W, Shafiq, M. M. I., Hanafi A. R., Puspa, L., \& Nor Azlida, A. (2016a). Algorithm for Combining Robust and Bootstrap In Multiple Linear Model Regression. Journal of Modern Applied Statistical Methods, 15(1), 884-892. doi: 10.22237/jmasm/1462077900

Ahmad, W. M. A. W, Arif, M. A., Nor Azlida, A., \& Shafiq, M. (2016b). An Alternative Method for Multiple Linear Model Regression Modeling, a Technical Combining of Robust, Bootstrap and Fuzzy Approach. Journal of Modern Applied Statistical Methods, 15(2), 743-754. doi: 10.22237/jmasm/1478004120.

Chen, C. (2002). Robust Regression and Outlier Detection with the ROBUSTREG Procedure. Proceedings of the 27th SAS Users Group International Conference. Cary NC: SAS Institute, Inc.

Huber, P.J. (1973). Robust regression: Asymptotics, conjectures and Monte Carlo. The Annals of Statistics, 1(5), 799-821. doi: 10.1214/aos/1176342503

Linear Regression. (n.d.) In Wikipedia. Retrieved from: https://en.wikipedia.org/wiki/Linear_regression\#Simple_and_multiple_regression.

Lockwood, C. M. \& Mackinnon, D. P. (1998). Bootstrapping the standard 7 error off the mediated effect. Proceedings of the 23rd Annual Meeting of SAS 8 Users Group International. Cary, NC: SAS Institute, Inc.

Rousseeuw, P. J. (1984). Least Median of Squares Regression. Journal of the American Statistical Association, 79(388), 871-880. doi: 10.2307/2288718

Rousseeuw, P. J. and Yohai, V. (1984). Robust Regression by Means of S estimators. In J. Franke, W. Härdle, and R. D. Martin, Eds. Robust and Nonlinear Time Series Analysis (Lecture Notes in Statistics 26). New York: Springer Verlag, pp. 256-274. doi: 10.1007/978-1-4615-7821-5_15

Stromberg, A. J. (1993). Computation of high breakdown nonlinear regression parameters. Journal of the American Statistical Association, 88(421), 237-244. doi: 10.1080/01621459.1993.10594315

Susanti, Y., Pratiwi, H., Sulistijowati, S., \& Liana, T. (2014). M Estimation, S Estimation, and MM estimation in Robust Regression. International Journal of Pure and Applied Mathematics, 91(3), 349-360. doi: 10.12732/ijpam.v91i3.7 
SHAFIQ ET AL.

Yohai V. J. (1987). High Breakdown Point and High Efficiency Robust Estimates for Regression. Annals of Statistics, 15(2), 642-656. doi:

10.1214/aos/1176350366 